\title{
Petrología de las concreciones carbonatadas de Jaizkibel (Eoceno, Gipuzkoa)
}

\author{
Jaizkibelgo konkrezio korbonatatodunen petrologia (Eozenoa, Gipuzkoa) \\ Petrology of carbonate concretions of Jaizkibel (Eocene, Gipuzkoa)
}

\author{
Irati Nogales ${ }^{1 *}$, Arantza Aranburu' ${ }^{1,2}$, Michel Molia $^{3}$ \\ ${ }^{1}$ Dpto. Mineralogía y Petrología, Facultad de Ciencia y Tecnología, UPV/EHU. Sarriena s/n, 48980 Leioa. \\ ${ }^{2}$ Geo-Q/Sociedad de Ciencias Aranzadi, Leioa. \\ ${ }^{3}$ Ch. du Grand Basque 4, 64100 Bayonne \\ * Correspondencia: arantza.aranburu@ehu.es
}

\section{RESUMEN}

Este artículo aporta información petrológica sobre las denominadas "paramoudras" del Eoceno de Jaizkibel, formación montañosa que pertenece a la Cadena Terciaria Costera que se encuentra cerca del límite con Francia, en Gipuzkoa. Aunque estas concreciones están presentes en todo el litoral guipuzcoano, la zona de muestreo se localiza en Irupuntxa, donde afloran de forma espectacular. Las muestras estudiadas han sido 3 nódulos en total, mediante 9 láminas delgadas. Tras el estudio descriptivo macroscópico y petrológico realizado se ha podido observar que los nódulos no son concreciones silíceas sino carbonatadas. Por ello, el término paramoudra no sería correcto ya que esa denominación es utilizada para concreciones silíceas. Se propone, en cambio, utilizar el término pseudoparamoudra.

PALABRAS CLAVE: Concrección, paramoudra, petrología, Jaizkibel, Eoceno.

\section{LABURPENA}

Artikulu honek Jaizkibelen azaleratzen diren Eozeno garaiko paramoudra deituriko konkrezioei buruzko informazio petrologikoa gehitzen du. Jaizkibel, formazio menditsua, Tertziario garaiko Kostako Mendikateen parte da eta Frantziaren mugatik gertu dago, Gipuzkoan hain zuzen ere. Nahiz eta konkrezio hauek itsasertz osoan zehar agertu, laginketa gunea Irupuntxa izan zen bertako azaleramendua baita liluragarriena. Ikertutako laginak 3 izan dira guztira eta 9 xafla meheen azterketa egin da. Deskribapen makroskopiko eta azterketa petrologikoaren bitartez ikusi ahal izan da noduluak ez direla silizezko konkrezioak, paramoudren definizioan agertzen den gisara, karbonatodunak direla baizik. Beraz, paramoudra terminoa ez da egokia eta "pseudo-paramoudra" erabiltzea gomendatzen da.

GAKO-HITZAK: Konkrezio, paramoudra, petrologia, Jaizkibel, Eozeno.

\section{ABSTRACT}

This paper provides petrological information about paramoudras of the Eocene from Jaizkibel, montain formation belong to Tertiary Coast Range, which is in the boundary with France, in Gipuzkoa. These concretions appear in all the coast of Gipuzkoa, but the sampling area was Irupuntxa, where they are more spectacular. The concretion samples studied were 3 by 9 thin sections. After macroscopic description and petrological study of the concretions, the main conclusion is that the nodules are not siliceous, and they are carbonated. Thus the term paramoudra is not suitable because this expression is used to siliceous concretion and we suggest to use "pseudo-paramoudra" (or pro-paramaoudra in english).

KEY WORDS: Concretion, paramoudra, petrology, Jaizkibel, Eocene.

\section{INTRODUCCIÓN}

El monoclinal de Jaizkibel se encuentra en el noreste del territorio guipuzcoano, cerca del límite con Francia. Esta formación montañosa con alineación NE-SW pertenece a la Cadena Terciaria Costera y tiene una dimensión de 2.424 ha y alcanza una altura máxima de $547 \mathrm{~m}$.

Parece ser que su nombre de origen era Oleartzu y que Jaizkibel era la parte trasera del monte, derivando de la conjunción de las palabras haitz gibel. Es un lugar de gran interés naturalístico, destacado en la Red Natura 2000 y en el inventario de LIG de la CAPV. El objetivo de este trabajo es describir y contribuir a conocer la causa de las concreciones decimétricas que afloran dentro de los niveles siliciclásticos, más areniscosos, del Eoceno. Para ello se ha realizado un estudio de las muestras facilitadas por Michel Molia, partiendo de una descriptiva mediante lupa binocular, y estudios petrológicos mediante microscopio óptico.

\section{CONTEXTO GEOLÓGICO}

El entorno estudiado se sitúa en el límite oeste de los Pirineos, dentro de la Cuenca Vasco-Cantábrica (CVC), más concretamente en la parte noreste. Esta cuenca se crea mediante una fase de distensión tectosedimentaria en la época Jurasico-Cretáceo, en una fase rift relacionada con la apertura del Golfo de Vizcaya (Vera et al., 2004).

La característica más destacada de la CVC, debido a la fuerte subsidencia tectónica sufrida, es la gran potencia de la sucesión Mesozoica, en particular la del Cretácico, con un espesor acumulado que ha sido estimado entre 12.000 y 17.000 m (EVE, Jaizkibel 40 - IV, 1991). La CVC recibió aportes marinos hasta el Eoceno superior (quizás hasta el Mioceno), periodo en el que dio comienzo la sedimentación continental, resultado de la emersión provocada por la Orogenia Alpina.

En la actualidad, la CVC se encuentra dividida en tres partes tectosedimentarias (Vera et al., 2004): Arco Vasco, 
Plataforma Norcastellana, Surco Navarro-Cántabro (Fig. 1). En Jaizkibel afloran materiales pertenecientes a la unidad tectónica de San Sebastián, de edades entre el Maastrichtiense y el Eoceno inferior (EVE, Jaizkibel 40 - IV, 1991) y que pertenecen al norte del Arco Vasco (Fig. 1). Todos ellos son de carácter marino.

Las principales litologías de la cadena costera están formadas por crestones areniscosos métricos, que forman resaltes en el terreno, y alternancia de lutitas/margas y finas capas de areniscas, que afloran en zonas más deprimidas. Esta alternancia siliciclástica aflora en la parte alta y vertiente Norte del Monte Jaizkibel y son de edad Eocena. Tras la fase de compresión ligada a la Orogenia Alpina la sucesión estratigráfica presenta una orientación N40-60E.

Son escasos los estudios geológicos detallados realizados en el entorno de Jaizkibel y/o sobre las unidades detríticas equivalentes que afloran en Igueldo, por ejemplo. Por tanto, la descriptiva estratigráfica general está basada, fundamentalmente, en el informe realizado por EVE en los mapas 1:25.000 de la Comunidad Autónoma Vasca (CAV) y en Pujalte et al. (2000).

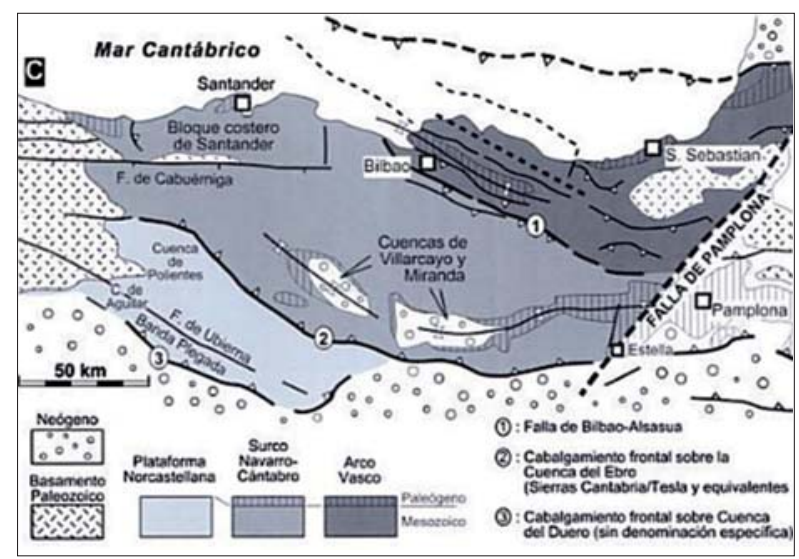

Fig. 1. - División de la Cuenca Vasco-Cantábrica: Arco Vasco, Surco Navarro-Cántabro y Plataforma Norcastellana. Fuente: Geología de España, 2004. 1. Irudia. Eusko Kantauriar Arroaren banaketa: Euskal Arkua, Nafar-Kantauriar hildoa eta Ipargaztela Plataforma. Iturria: Geología de España, 2004.

\section{Descripción estratigráfica}

Los materiales terciarios son los que afloran con mayor extensión y forman una sucesión terrígena potente donde se han diferenciado dos litologías principales (Fig.3): (1) areniscas de cemento calcáreo estratificadas con graduación positiva y dispuestas en bancos potentes de orden métrico y (2) lutitas que se alternan con las areniscas citadas anteriormente. Posee una tectónica de zócalo que no es visible pero la limitación de bloques hace que haya cambios de potencia en las series sedimentarias.

El registro sedimentario es limitado en el tiempo pero continuo. Los materiales del Flysch del Terciario son turbidíticos y fueron depositados en condiciones de transgresión marina. La sedimentación se dio en una amplia cuenca marina dónde la entrada de sedimentos se producía principalmente desde las plataformas "pirenaicas".

\section{Condiciones tectosedimentarias}

La paleogeografía del Cretácico superior-Paleógeno inferior del dominio oeste pirenaico se puede simplificar y entender como una vaguada de gran profundidad estirada en dirección E-W (Fig. 2). En el norte y en el sur estaba flanqueada por áreas amplias y relativamente llanas, que correspondían a márgenes distales de cuencas foreland. Durante la mayor parte del Cretácico superior, el área se situaba en el sur de la vaguada y mantenía la geometría de una rampa, mientras que durante el Paleógeno inferior ( $\mathrm{Pa}$ leoceno y Eoceno medio) fue invadido repentinamente por plataformas carbonatadas. Durante el Paleoceno, las plataformas carbonatadas también dominaron las áreas llanas del norte, aunque la sedimentación siliciclástica aumentó de manera importante durante el Eoceno. Las zonas de cuenca, además de la lluvia hemipelágica, recibieron tanto aportes de carbonatos de grano grueso como de sedimentos siliciclásticos. Estos sedimentos, de cualquier manera, representan la resedimentación de los sedimentos de las plataformas carbonatadas flanqueadas. Estas últimas proceden en su mayoría del Pirineo oriental, el cual estaba parcialmente emergido durante el Paleógeno inferior y estaba sometido a una erosión activa. Algunos de los depósitos siliciclásticos fueron exportados en sistemas fluvio-deltaicos que después se desarrollaron en cuencas piggy-back. El resto de los materiales fueron exportados al fondo de las cuencas, donde fueron acumulados en grandes sistemas turbidíticos siliciclásticos (Pujalte et al., 2000).

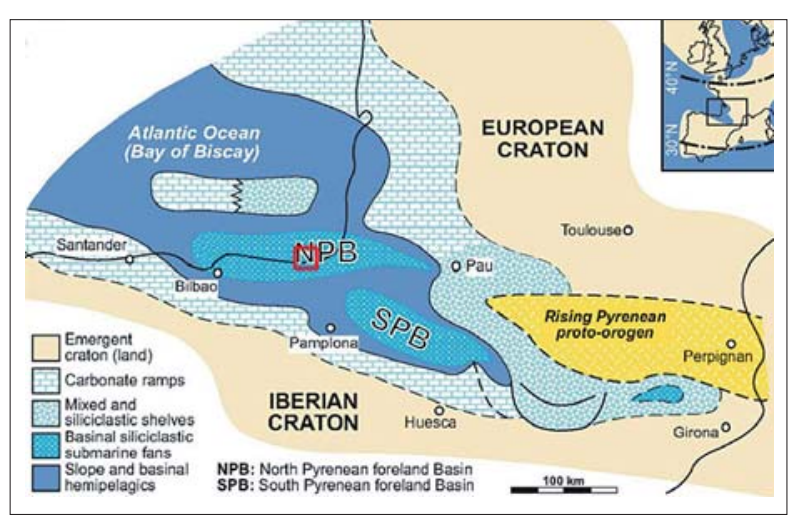

Fig. 2. - Marco paleogeográfico de Europa y Pirineos durante el Eoceno. La localización actual de Jaizkibel se encuentra marcado mediante un recuadro de color rojo. Imágenes modificadas de Payros \& Martínez (2013).

2. Irudia. Europa eta Pirinioen eskema paleogeografikoa. Jaizkibelgo gaur egungo kokapena karratu gorri baten bitartez adierazita agertzen da (Payros \& Martinez, 2013-tik eraldatutako irudia).

Desde el final del Cretácico hasta el Eoceno superior, se dio el desplazamiento de la Placa Ibérica hacia el Norte unos 150 km en relación a la Placa Europea. El cambio de condiciones trajo efectos sedimentarios y paleogeográficos:

1. Hacia el final del Danés comienza una actividad tectónica dentro de la cuenca que favorece la destrucción parcial de esas plataformas. Durante esta época se generaron cañones submarinos que se rellenaron durante el Thanetiense. La sedimentación fue prácticamente continua, los fenómenos erosivos 
basales estarían relacionados con un descenso relativo del nivel marino.

2. En el Ypresiense se produce una homogeneización de la sedimentación generándose potentes series flyschoides y sistemas turbidíticos. Estos últimos constituyen el "Flysch terciario" y constituían grandes conos submarinos depositados en condiciones de transgresión marina (EVE, Jaizkibel 40-IV, 1991).

Esta serie sugiere que la cuenca turbidítica del Eoceno debía tener una extension de unas decenas de kilómetros cuadrados (EVE, Jaizkibel 40-IV, 1991).
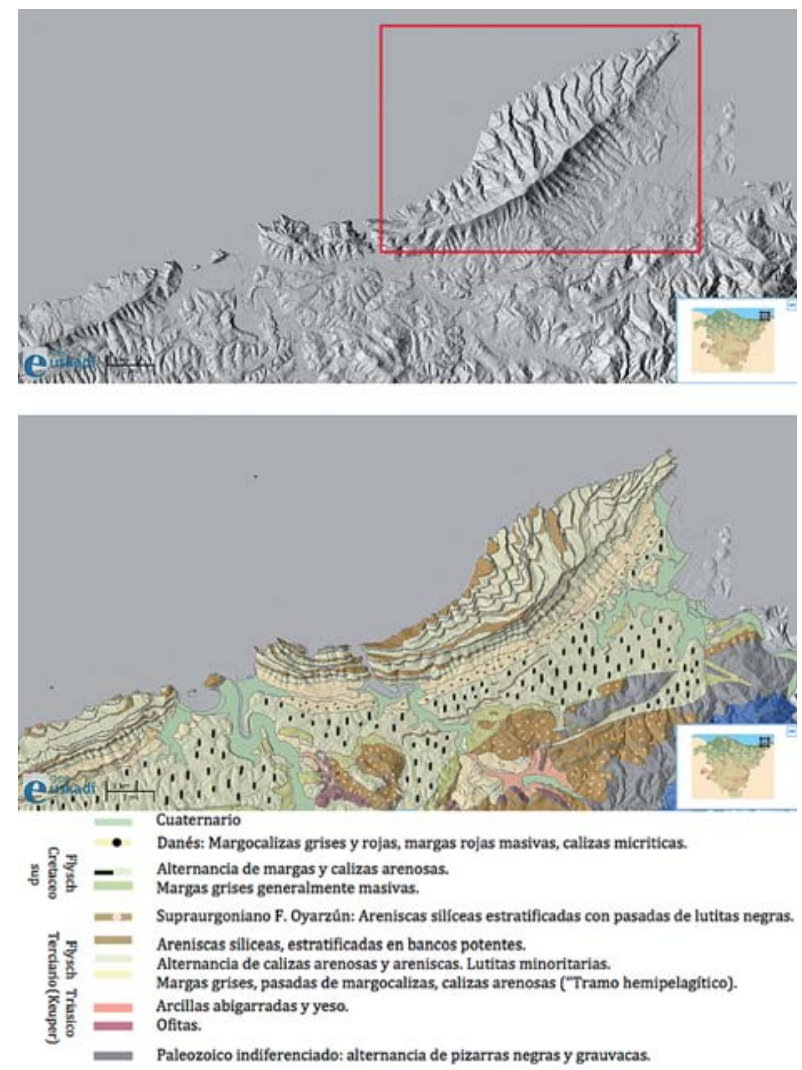

Fig. 3. - a) Imagen LIDAR de la zona de Jaizkibel donde esta alineación montañosa se encuentra marcada mediante un recuadro rojo. b) Imagen donde aparece superpuesta la geología de la zona (Imágenes modificadas del visor Geoeuskadi).

3. Irudia. a) Jaizkibel guneko lidar argazkia, mendilerroa karratu gorri baten bitartez adierazita agertzen da. b) Guneko geologia gainjarrita agertzen den irudia (Geoeuskadi bisoretik eraldatutako irudiak).

\section{OBJETIVOS}

Las areniscas de Jaizkibel son conocidas tanto por su colorido (minerales/aportes de hierro) como por las diversas formas de erosión que presentan. Algunas de ellas, localizadas en la zona costera, son muy espectaculares constituyendo un lugar de indudable valor geológico indudable (Lugares de Interés Geológico, de la CAPV, LIG115, LIG136, www.irekia.euskadi.net).

En los últimos años, han sido varias las notas publicadas por Aranzadi en torno a las "paramoudras de Jaiz- kibel" (Galan et al., 2009, entre otros). Estas concreciones se desarrollan en areniscas carbonáticas y adoptan diferentes formas: esféricas, cilíndricas, serpentiformes, ánforas... Presentan un cordón central de pequeño diámetro (5-7 mm), que se asemeja a una bioturbación. La concreción es de carácter envolvente y se desarrolla a partir del centro o bioturbación. Pueden llegar a tener 2$3 \mathrm{~m}$ de desarrollo vertical y 6-8 $\mathrm{m}$ de subhorizontal (Galan et al., 2009), aunque los más comunes son de escala centimétrica. En el caso de las formas esféricas los tamaños varían entre $10-20 \mathrm{~cm}$ y $1 \mathrm{~m}$ de diámetro, con un promedio en torno a $55 \mathrm{~cm}$ (Galan et al., 2008). Según estos autores, basándose en los trabajos de Bromley (1975) y Bromley et al. (1975), las paramoudras son concreciones silíceas (madriguera) construidas alrededor de Bathichnus paramoudrae.

El objetivo de este trabajo es describir y conocer la razón de estas concreciones decimétricas que afloran en los niveles siliciclasticos del Eoceno más areniscosos, a partir del estudio petrológico comparativo de las distintas partes de las concreciones y la roca-caja.

\section{ÁREA Y MÉTODOS DE ESTUDIO}

Las concreciones ligadas a la serie siliciclástica terciaria afloran en todo el litoral Gipuzkoano, desde Jaizkibel hasta el ratón de Getaria, pasando por el monte Ulia e Igeldo, pero el lugar donde afloran de manera más espectacular es en Irupuntxa (Jaizkibel) (X. 592.380,60; Y 4.802,917,06; Nivel 16) (Fig. 4). El lugar toma una extensión de 14 ha y en él desemboca el arroyo Erantzintxabaleta.

La metodología empleada para el estudio de las concreciones se ha centrado en la descriptiva macroscópica de las muestras de mano, con la ayuda de una lupa binocular Leica ZOOM 2000, y el estudio petrológico de 9 láminas delgadas, dos de la roca caja y las demás de las concreciones mediante microscopio petrográfico Olympus BX50.

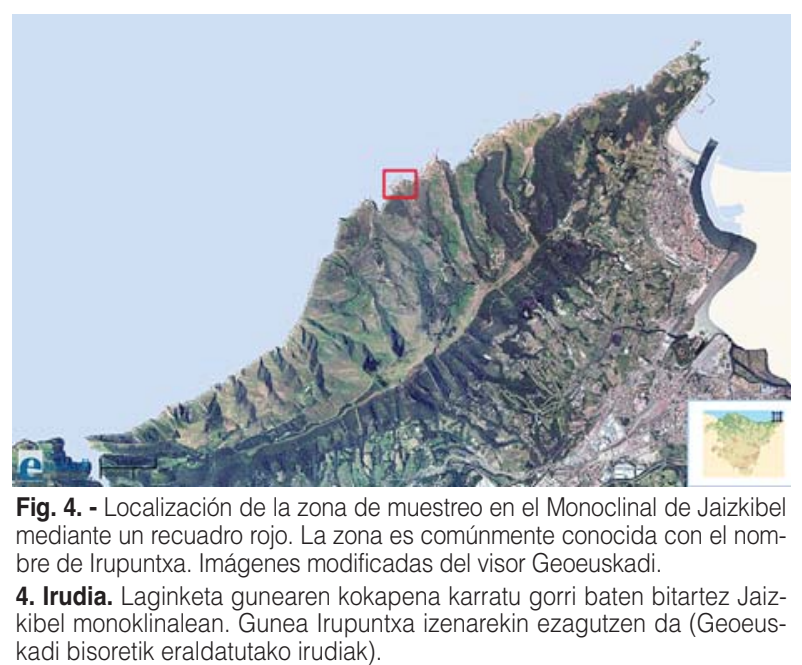



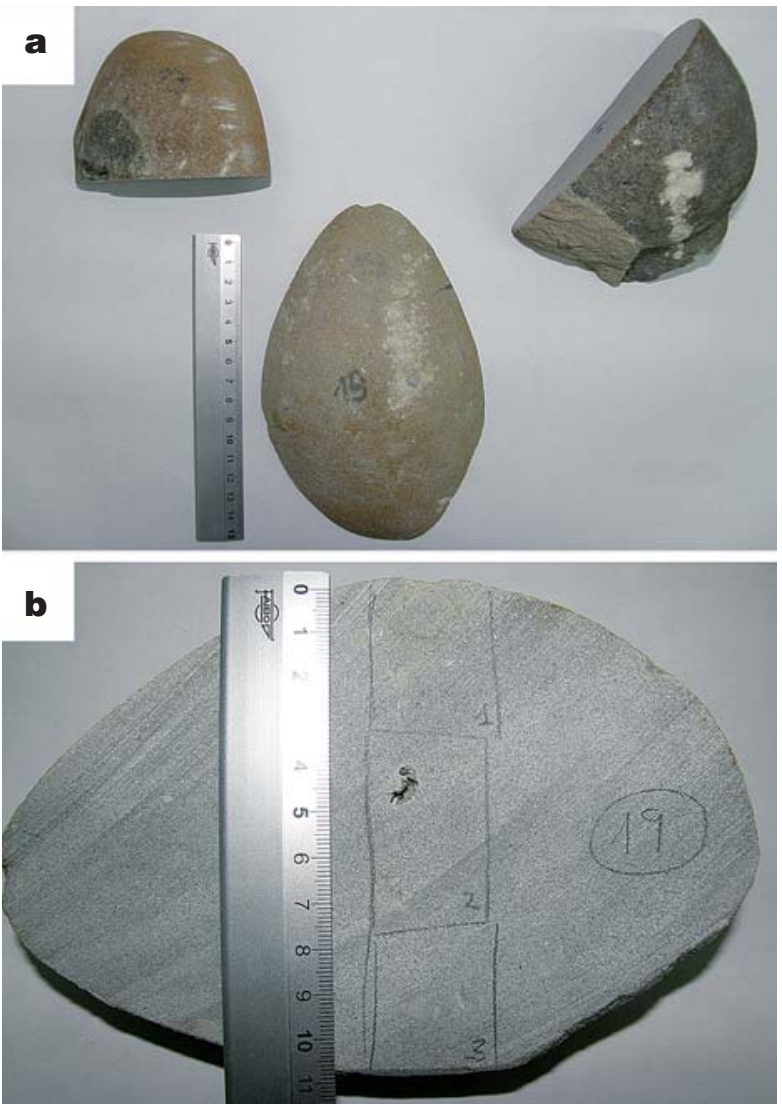

Fig. 5. - Nódulos carbonatados. A) Morfología y tamaño de los nódulos. B) Posición de las láminas delgadas en el nódulo. La primera lámina toma parte del cordón central para ver posible tipo de tránsito, gradación o erosión. Las otras dos abarcan el resto de la concreción.

5. Irudia. Karbonatodun noduluak. a) Noduluen tamaina eta morfologia. b) Xafla meheen kokapena noduluan. Lehenengo xaflak tutu zentrala barne hartzen du, iragatea, gradazioa edo higadura badagoen ikusteko. Beste bi xaflek konkrezioaren gainontzeko azalera hartzen dute.
Las concreciones estudiadas han sido 3 en total. Presentan formas elipsoidales de $17 \times 11 \mathrm{~cm}$ (Fig. 5a). Macroscópicamente, el cordón o zona central se diferencia por una mayor proporción de arcilla de color verdoso. El cordón tiene forma ovalada de dimensión de $2 \times 1 \mathrm{~cm}$, con un espesor medio de $2 \mathrm{~mm}$. El interior y el exterior del cordón muestran las mismas características: color marrón claro con una trama comprendida mayormente por cuarzos bastante angulosos. Estos cuarzos muestran las mismas características que los de la zona central pero en este caso la proporción de arcilla es mayor. Microscópicamente, el cordón tiene un tamaño de 1,2 cm y muestra una morfología circular (Fig. 6a, 6b). Se puede observar menor tamaño de grano en las inmediaciones del interior de la bioturbación (Fig. 6c, 6d). Al igual que se puede ver macroscópicamente, la trama del cordón es idéntica a la del nódulo y está constituida por cuarzo, feldespato potásico, glauconita y moscovita. La única diferencia es la cantidad de filosilicatos, que constituye la matriz, ya que estos son abundantes y marcan el perímetro del cordón.

Al realizar las láminas delgadas de los nódulos se ha intentando abarcar todos los diferentes tramos haciendo láminas de manera transversal. Una de las láminas de la concreción ha sido realizada tomando parte del cordón central o la bioturbación, para poder ver si hay algún tipo de tránsito, gradación o erosión. (Fig. 5b).

\section{RESULTADOS \\ Petrología de los Nódulos/Concreciones}

Los nódulos están formados por areniscas de grano medio, de tipo protocuarcita (Selley, 1977), con una cementación diferencial por reemplazamiento de calcita. El tamaño de grano oscila entre $0,7 \mathrm{~mm}$ y 0,1 $\mathrm{mm}$, siendo la
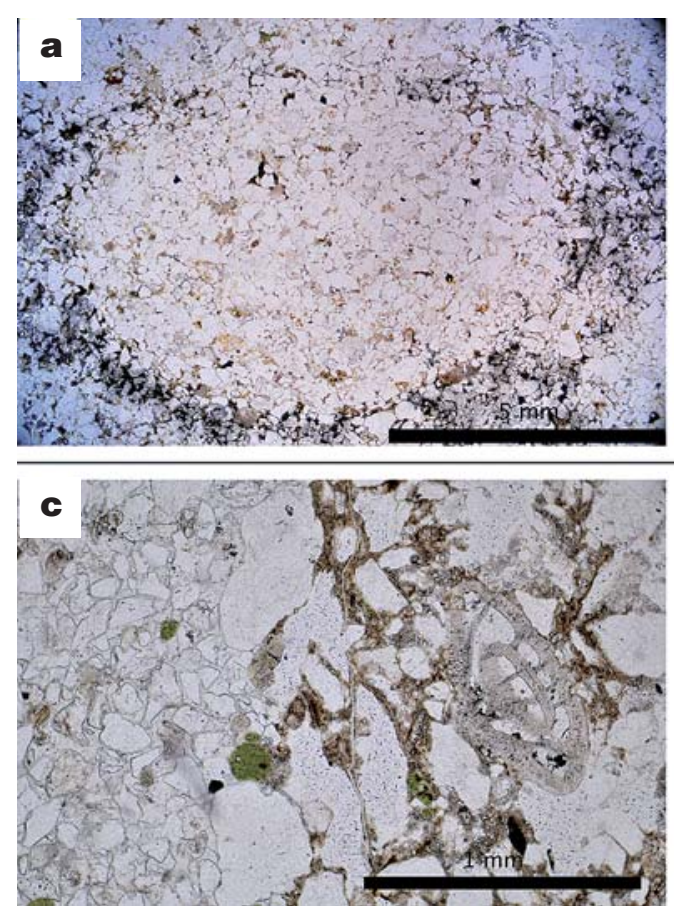
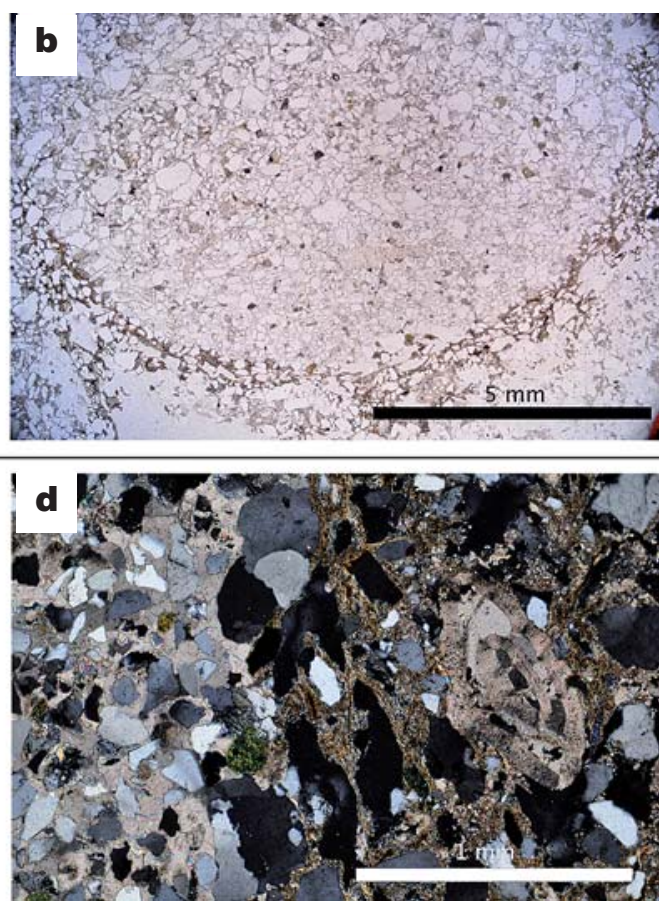

Fig. 6. - Imágenes de la bioturbación, el perímetro de éste está marcado por una mayor proporción de arcilla. A) Imagen de la bioturbación en la roca caja. B) Imagen de la bioturbación en el nódulo. C) Menor tamaño de grano en las inmediaciones de la bioturbación, PPL. D) Menor tamaño de grano en las inmediaciones de la bioturbación, XPL. 6. Irudia. Bioturbazioaren irudiak, hau buztin proportzio handiago batez adierazita agertzen da. a) Bioturbazioaren itxura arroka kaxan. b) Bioturbazioaren itxura noduluaren barnean. $\mathrm{C}$ Pikor tamaina txikiagoa bioturbaziotik gertu, PPL. d) Pikor tamaina txikiagoa bioturbaziotik gertu, XPL. 
media 0,4 mm (la más abundante). En cuanto a la morfología de las partículas de arena, muestran una baja esfericidad, son bastante angulosas y la selección es poorly sorted. La mineralogía de la trama está compuesta por granos de cuarzo, moscovita, glauconita y feldespato potásico. Además, también aparecen intraclastos carbonatados y bioclastos.

El cuarzo es el $90 \%$ de la trama, de éstos el $55 \%$ es monocristalino y el 35\% restante policristalino. El tamaño de grano de estos varía entre 0,7-0,1 mm, los mayores teniendo una tendencia a ser monocristalinos. Se observa una gran heterogeneidad en cuanto a la forma, ya que algunos son bastante angulosos mientras que el perímetro de otros está bastante bien redondeado.

La glauconita aparece en una proporción menor, siendo el $4 \%$ de la trama, al igual que el feldespato potásico. La moscovita es muy escasa y forma el $1 \%$ de la trama. El tamaño longitudinal de estos varia entre el 1,5$0,05 \mathrm{~mm}$, siendo el 0,5 mm el más abundante. Este mineral aparece adaptado a los demás granos.

En cuanto al contenido fosilífero se pueden encontrar fragmentos de albeolinidos, briozoos, foraminíferos aglutinadores, foraminíferos de tipo monoseriados y biseriados, placas y espinas de equinodermos, miliolidos y conchas (Fig. 7).

Los intraclastos son muy escasos, no llegan al 1\% de la trama y son fragmentos de marga. En el interior de algunos de ellos se pueden observar foraminíferos bentónicos. En cuanto a la matriz, se observa algo de pseudomatriz creada a partir de la deformación de los intraclastos. Pero lo que predomina en toda la lámina es la calcita de tamaño esparita (Fig. 8a)

La calcita, con cristales xenomorfos, se extiende por el nódulo de manera generalizada. Es el espacio intergranular el que se encuentra ocupado cristales poiquilotópicos (tamaño <0,3 mm) (Fig. 8b). A lo largo de la lámina delgada aparece sustituyendo los granos de cuarzo.

Son varios los procesos diagenéticos diferenciados en el interior de las concreciones:

1. La bioturbación muestra una morfología circular que comprende el tamaño de 1,2 mm en lámina delgada y ovalada de $2 \times 1 \mathrm{~cm}$ en la muestra de mano. Macroscópicamente y microscópicamente, se observa que la trama del cordón es idéntica a la del nódulo, dife-

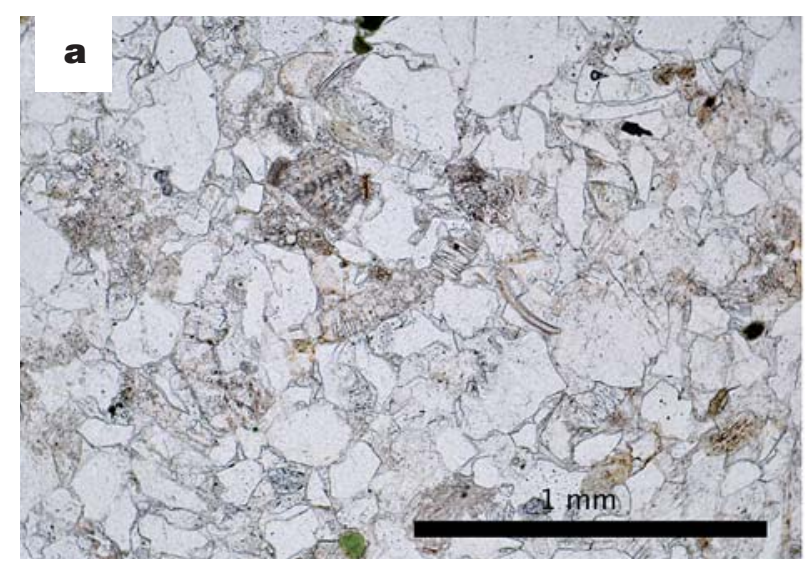

Fig. 7. - Contenido fosilífero del interior del nódulo.

7. Irudia. Nodulu barnean agertzen den fosilen edukia.
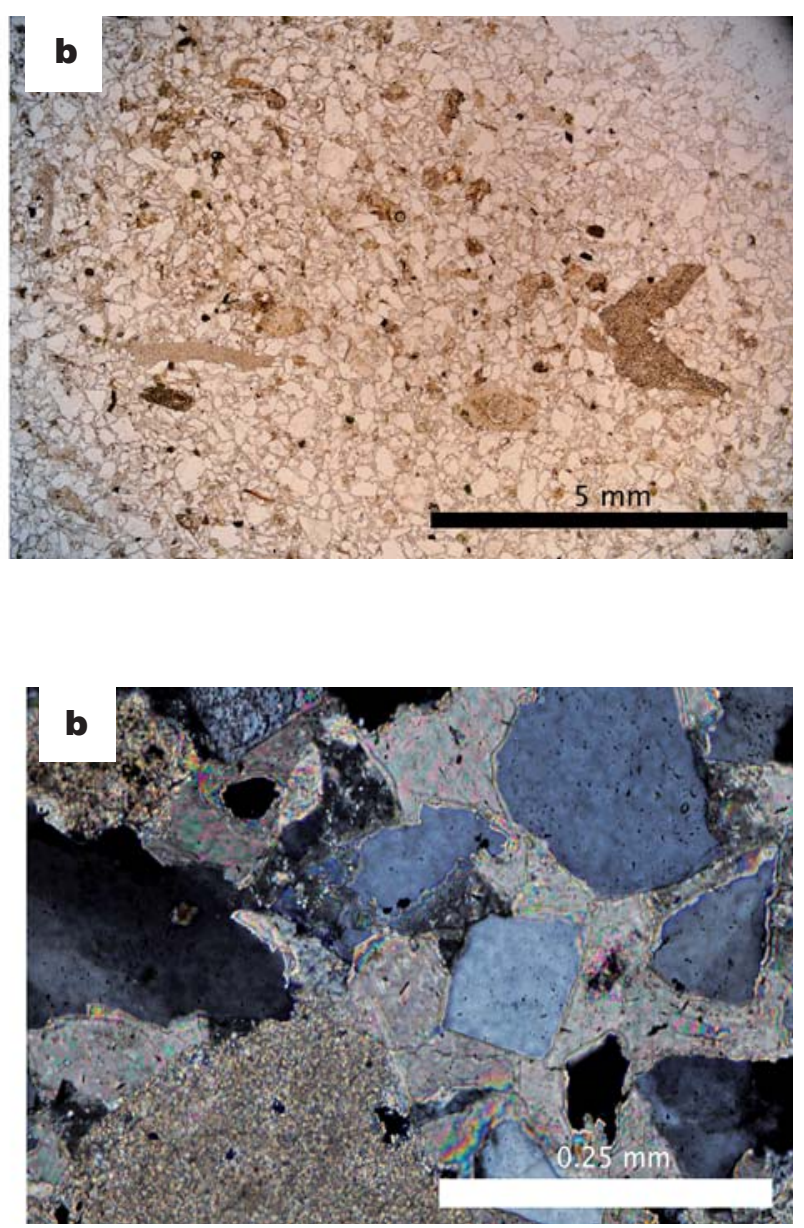

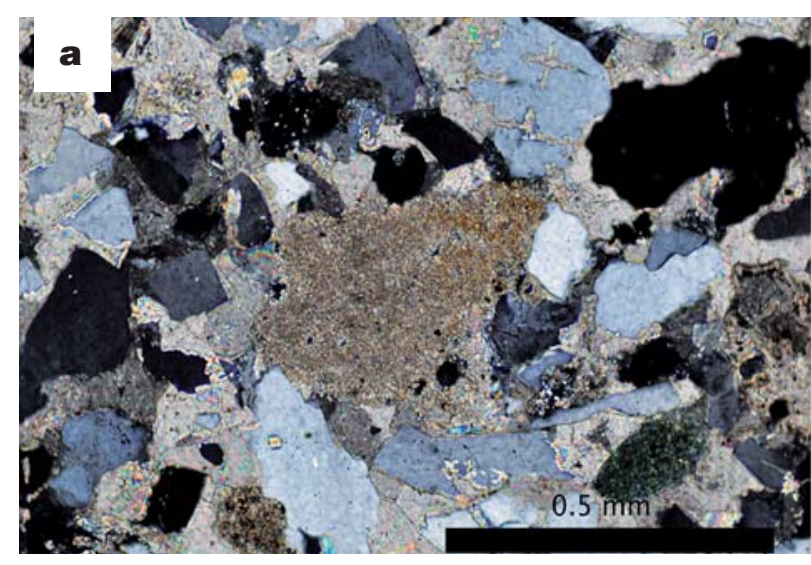

tos a) Intraclasto recristalizado rodeado de calcita poiquilotópica b) CrisFig. 8. - Pseudomatriz recristalizada creada a partir de la deforma
tales de calcita xenomorfos que ocupan el espacio intergranular.

8. Irudia. Birkristaldutako pseudomatriza intraklastoen deformazioen bitartez eratutakoak. a) Birkristaldutako intraklastoa kaltzita poikilotopikoz inguratuta. b) Pikorren hutsuneak betetzen dituen kaltzitazko kristal xenomorfoak. 
renciándose por la abundancia de la matriz formada por filosilicatos que marcan el perímetro del cordón.

2. El reemplazamiento comienza en un núcleo y va aumentando, hasta, en algunos casos, englobar los granos de alrededor (cristales poiquilotópicos) (Fig. 9).

3. La recristalización, tanto de la matriz de fango carbonatado, como de las placa de equinodermo, es de tipo equidimensional idiomorfo (Fig. 10).

\section{Petrología de la Roca Caja}

En el estudio petrográfico de la roca caja se puede observar que el tamaño de grano varía entre 0,6-0,1 mm, teniendo un tamaño medio de 0,3 mm. Por lo que nos encontramos frente a una arenisca siliciclástica de grano medio-fino.

La trama de la roca la componen cuarzo, feldespato potásico, glauconita, moscovita, biotita e intraclastos. Además de estos aparecen minerales pesados como turmalina o pirita. El más abundante es el cuarzo que comprende el $90 \%$ de la trama. El $80 \%$ de este cuarzo es monocristalino, por lo que el $20 \%$ restante es policristalino. La mayoría de los cuarzos monocristalinos enseña una extinción ondulante heredada. La glauconita comprende tamaños entre 0,3-0,1 mm y es el $2-3 \%$ de la trama. La moscovita es menos común y los tamaños oscilan entre el 1,2-0,1 mm. También aparecen intraclastos de arcilla que, debido a la compactación, aparecen deformados formando una pseudomatriz.

Esta roca es una protocuarcita, según Selley (1977), o subarcosa, según Pettijohn, Potter \& Siever (1973).

La textura de la roca es grano-soportada, con casi nula presencia de matriz detrítica, a excepción de las zonas bioturbadas donde relativamente incrementa la proporción de arcilla. Se observan vestigios de compactación por presión-disolución, mediante contactos suturados y contactos triples entre granos de cuarzo. El cemento, muy escaso, es de cuarzo y como es frecuente en las rocas siliciclásticas con poca matriz (<5\%, Dutton and Diggs, 1990), precipita alrededor de los granos, en el caso del sintaxial, y entre los granos, cuando es microcuarzo $(<0,1$ $\mathrm{mm})$ o chert.
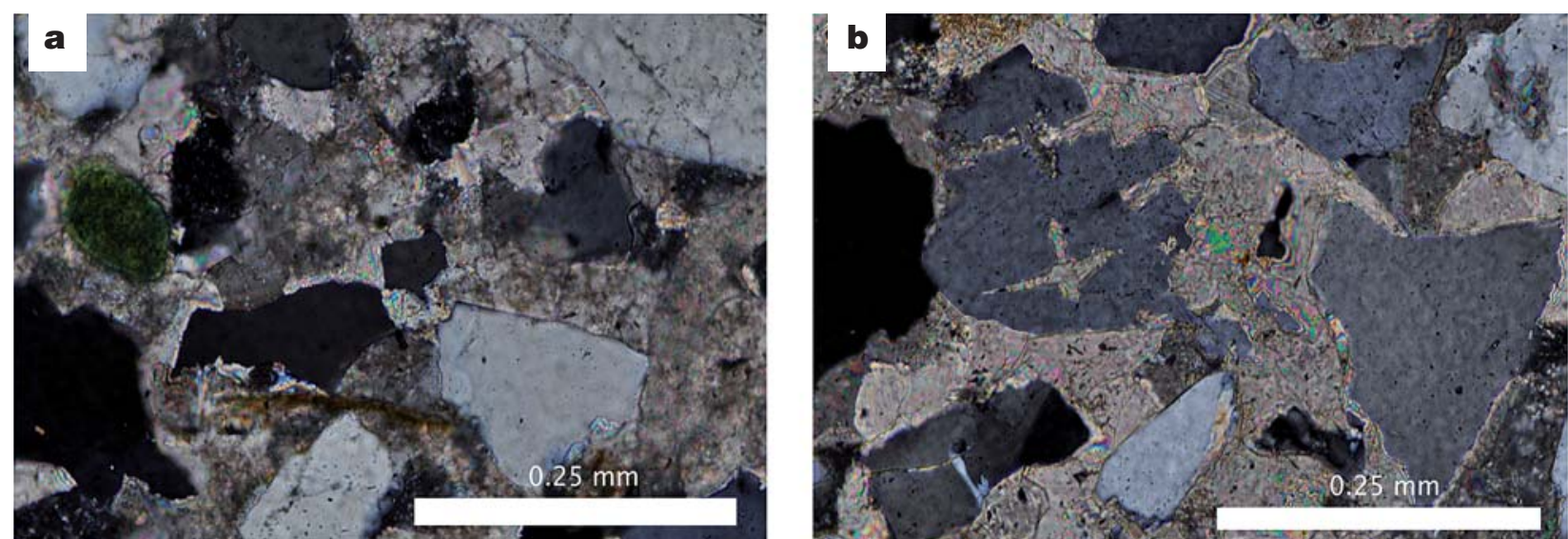

Fig. 9. - Reemplazamiento del cuarzo mediante la calcita en el interior del nódulo. A) Frontes de reemplazamiento. B) El reemplazamiento, además de darse en el exterior de los granos, también se da en el interior.

9. Irudia. Kaltzitaren bidezko kuartzoaren ordezkapena noduluaren barnean. a) Ordezkapen fronteak ikus daitezke. b) Ordezkapena pikorren kanpoaldean emateaz gain, barnekaldean ere ematen da.

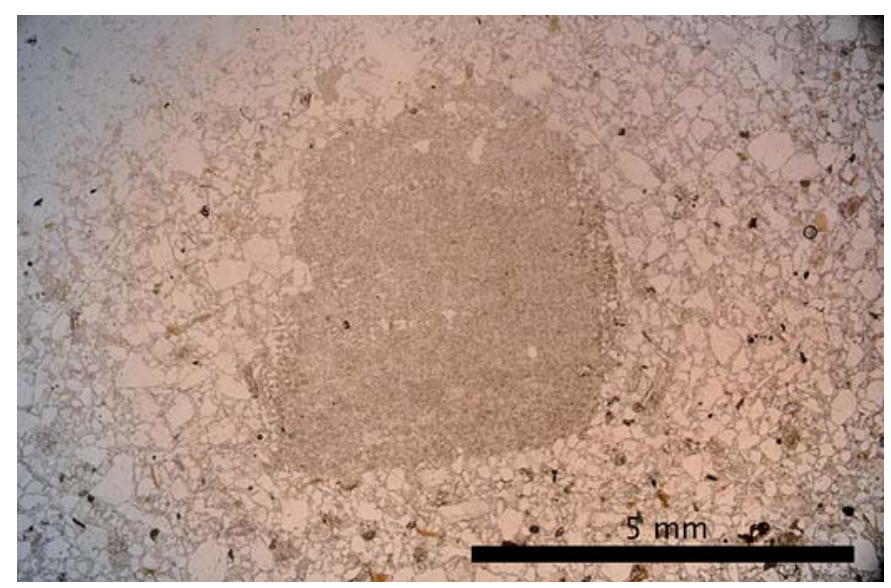

Fig. 10. - Recristalización del tipo equidimensional idiomorfo de una placa de equinodermo.

10. Irudia. Ekinodermatu plaka baten birkristaltzea. Birkristaltze hau ekidimensional idiomorfo motatakoa da. 
Son varios los procesos diagenéticos diferenciados en el interior de la roca caja:

1. La compactación: pseudomatriz (Fig. 11).

2. La presión-disolución: los rasgos de este proceso aparecen de manera generalizada mediante contactos suturados y contactos triples entre granos de cuarzo (Fig. 12).

3. La cementación: el cuarzo sintaxial precipita sobre los granos de cuarzo sin llegar a cubrir del todo. El microcuarzo equidimensional aparece en la modalidad de chert, rellenando alguna porosidad intergranular (Fig. 13).

\section{CONCLUSIONES}

Mediante el estudio descriptivo macroscópico y petrológico realizado en las distintas muestras de roca estudiadas, se ha podido observar que los nódulos (definidos como paramoudras por Galán et al., 2009) no son concreciones silíceas sino carbonatadas.

Aunque desde el punto de vista mineralógico el cuarzo es el mineral predominante, éste solamente se encuentra en las partículas detríticas. En este caso, la concreción se genera por la presencia de cristales de carbonato cálcico en torno a las bioturbaciones, quizás favorecido por una mayor proporción de matriz calcárea existente en el sedimento.

Por ello estas concreciones deberían ser denominadas pseudoparamoudras (paramoudra like). Breton, G. (2006) recomienda utilizar el término proparamoudras para las concreciones o paramoudras de naturaleza carbonatada. En lengua española, sin embargo, uno de los significados del prefijo pro- es ante, delante de, lo que podría llevar a entender, de forma errónea, que la calficicación es la fase anterior a la silicificación. Por ello entendemos que, al menos en español, la designación del termino pseudoparamoudra podría ser más adecuado.

En el estudio petrográfico de estas concreciones se ha podido observar que tanto la roca caja como el nódulo están compuestos por el mismo tipo de arenas (cuarzo, feldespato, glauconita y moscovita, mayormente), siendo la única diferencia la mínima cementación de naturaleza silícea en la roca caja y mayor presencia de carbonato en las concreciones. En la roca caja los granos aparecen con marcas de compactación (contactos suturados y puntos triples) mientras que en el nódulo se observan grandes cristales poiqui- lotópicos de calcita, como resultado de procesos de reemplazamiento (de la sílice, entre otros), y presencia de matriz sedimentaria. La roca caja tiene una textura grano-soportada, mientras que el nódulo es matriz-soportada.

La mayor proporción de matriz en las concreciones puede estar relacionada con la acción de la bioturbación y mezcla de sedimentos. La matriz, incorporada al sedimento mediante la bioturbación, podría ser el precursor de la carbonatación.

Comparando la historia diagenética de la roca con la de los nódulos podemos inferir una secuencia compuesta por: sedimentación de las arenas turbidíticas, bioturbación, carbonatación, compactación y cementación silícea.

1. Sedimentación: se dio en una cuenca turbidítica en un ambiente de transgresión marina. Los nódulos, únicamente se encuentran en los niveles de rellenos de canal microconglomeráticos y areniscosos de tamaño de grano medio-grueso. El aporte bioclástico a las arenas procede de las plataformas someras que bordeaban la cuenca. La sedimentación autóctona está presente a lo largo de toda la secuencia y en las distintas litologías descritas. La bioturbación puede dar lugar a la mezcla de sedimentos, introduciendo matriz (de carácter margoso) en el interior del nivel más arenoso del relleno de canal.

2. Carbonatación: en los lugares donde abunda la matriz de naturaleza carbonatada se da la recristalización, creando de esta manera los nódulos. La formación de los cristales de esparita durante la diagénesis fue temprana, ya que no se observan huellas de compactación física o modificación de la fábrica por carga o presión tectónica posterior (la roca caja, sin embargo, sí presenta). La recristalización inicial de la matriz pudo dar pie a los procesos de reemplazamiento, por incorporación de carbonato procedente de la compactación de las margas y la litificación.

3. Compactación y Presión-Disolución: los sedimentos soportaron una gran compactación al disminuir el espacio en el que se encontraban. En este proceso, mediante contactos triples y contactos saturados (relación presióndisolución) se consigue adecuar al espacio. De esta manera se crearon fluidos sílice.

4. Silicificación: este proceso tiene lugar en las areniscas donde la compactación no ha cerrado del todo la porosidad. Es muy minoritario, y de carácter isoquímico, donde el cemento de sílice procede de la disolución por presión de los propios granos (detríticos) de la trama.
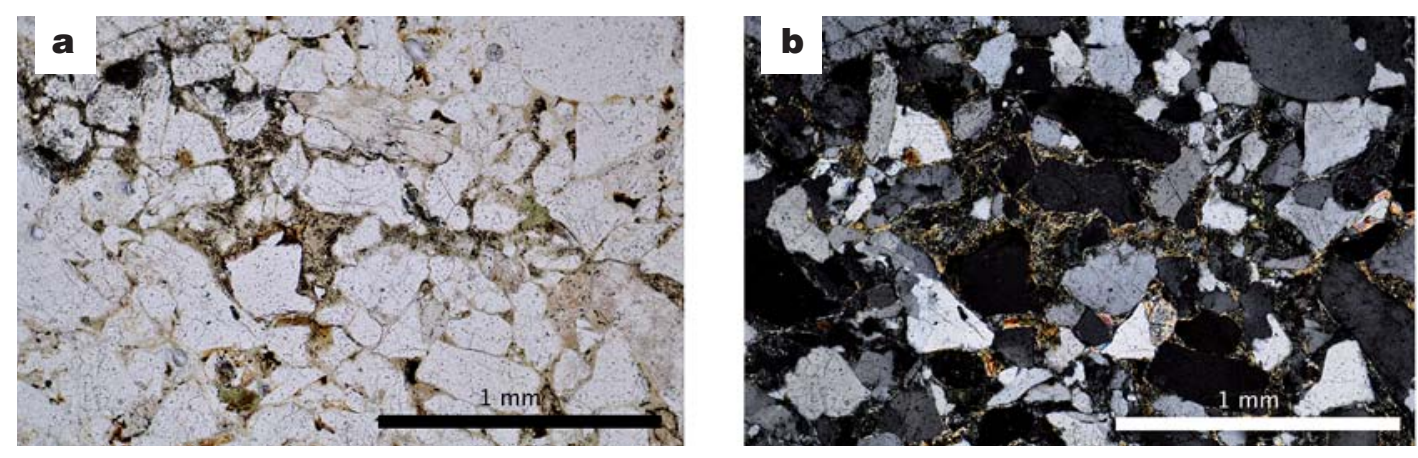

Fig. 11. - Zona bioturbada donde la proporción de arcilla incrementa. A) PPL. B) XPL. 11. Irudia. Bioturbazioa jasandako gunea, bertan buztinezko proportzioa handiagoa da. a PPL. b) XPL. 

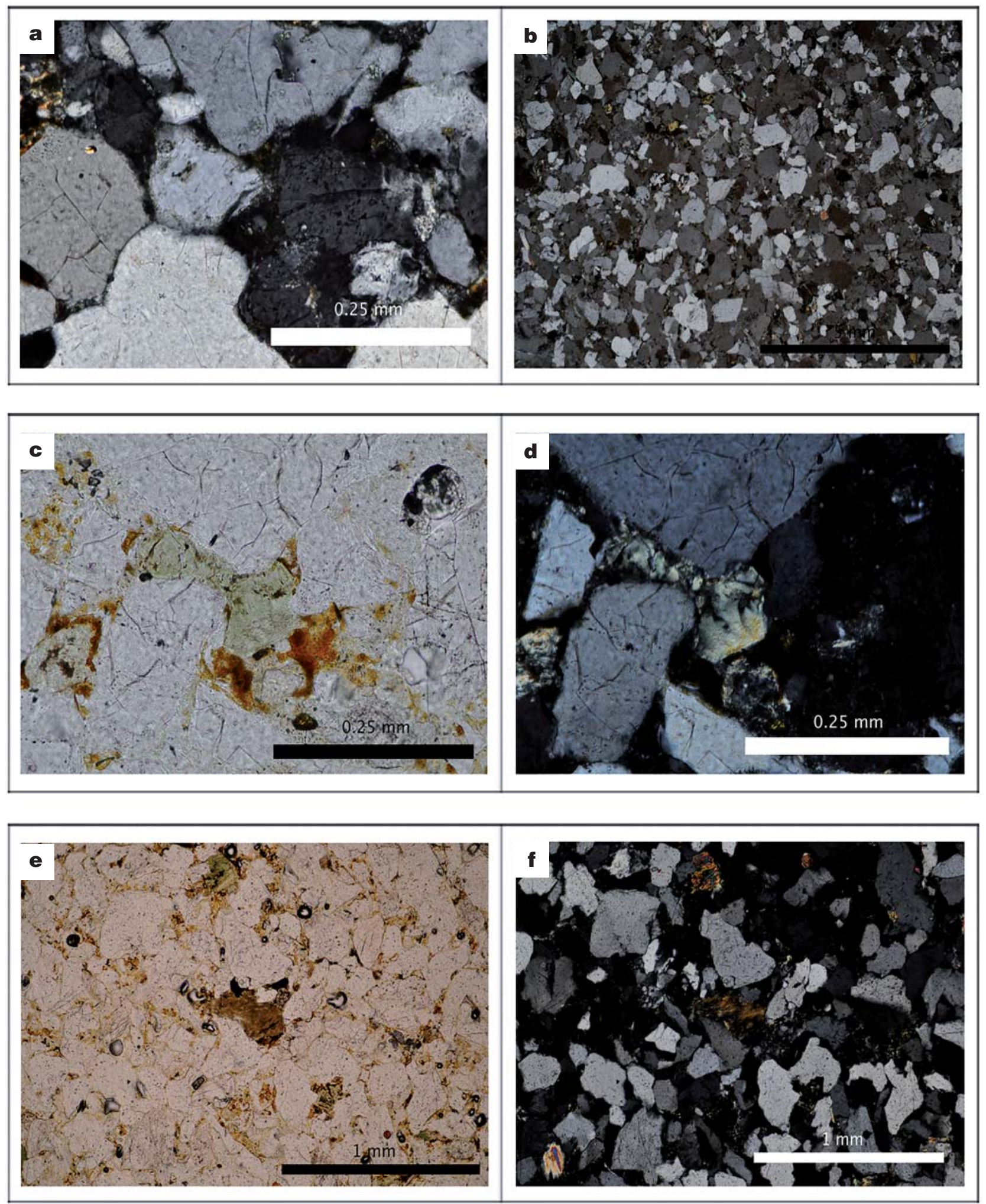

Fig. 12. - Compactación. a) Contacto triple entre granos de cuarzo monocristalinos. b) Contactos puntuales, triples y suturados. c) Clorita deformada tras la compactación entre granos de cuarzo, PPL. d) Clorita deformada tras la compactación entre granos de cuarzo, XPL. e) Pseudomatriz entre granos de cuarzo, PPL. f) Pseudomatriz entre granos de cuarzo, XPL

12. Irudia. Trinkadura. a) Kontaktu hirukoitza kuartzo monokristalen pikorren artean. b) Kontaktu puntual, hirukoitz eta suturatuak. c) Kuartzozko pikorren artean deformatutako klorita, PPL. d) Kuartzozko pikorren artean deformatutako klorita, XPL. e) Intraklastoen bitartez, kuartzozko pikorren artean, garatutako pseudomatriza, PPL. f) Intraklastoen bitartez, kuartzozko pikorren artean, garatutako pseudomatriza, XPL. 


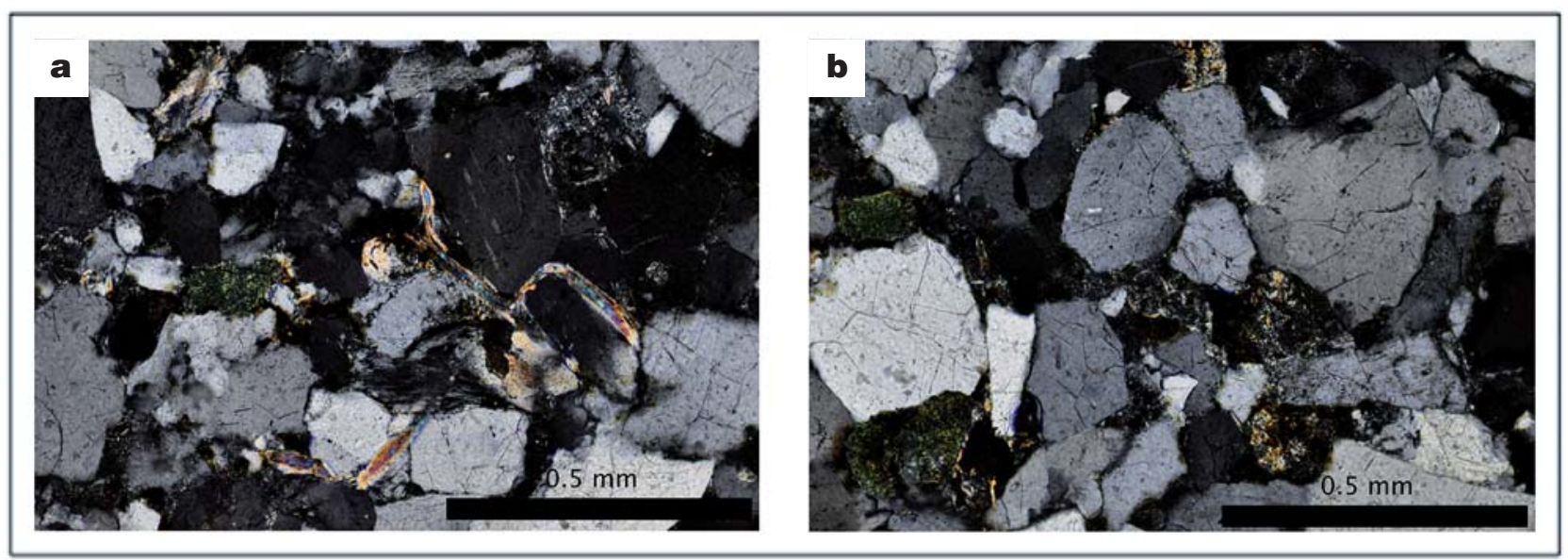

Fig. 13. - Microcuarzo equidimensional. a) El microcuarzo equidimensional aparece en la modalidad de chert; además, se observa cómo la moscovita se encuentra totalmente plegada y adecuada a los granos del entorno. b) El microcuarzo aparece rellenando la porosidad intergranular. En su interior hay un foraminífero bentónico.

13. Irudia. Mikrokuartzo ekidimentsionala. a) Mikrokuartzo ekidimentsionala chert moduan agertzen da, gainera, moskovita erabat tolestuta dagoela ikus daiteke inguruko pikorrei erabat egokituta. b) Pikorren arteko hutsunea betez agertzen da mikrokuartzoa, bere barnean foraminifero bentoniko bat agertzen delarik.

\section{BIBLIOGRAFÍA}

Breton, G. 2006. Paramoudras... Et autres concrétions autor d'un terrier. Bull. Inf. Géol. Bass. 43(3): 18-43.

Dutton, S. P., T.N. Diggs. 1990. History of quartz cementation in Lower Cretaceous Travis Peak Formation, east Texas. J. Sediment. Petrol. 60: 195

Ente Vasco de la Energía. 1991. Mapa geológico del País Vasco, Irun 41 - III. Escala 1:25.000. EVE.

Ente Vasco de la Energía. 1991. Mapa geológico del País Vasco, Jaizkibel 40 - IV. Escala 1:25.000. EVE.

Galán, C., Molia, M., Nieto, M. 2009. Paramoudras en arenisca de la Formación Jaizkibel. Disponible en Web: http://www.aranzadi.eus/fileadmin/webs/Publicaciones/pdfs/Galan-Molia.Paramoudras.pdf
Galán, C., Molia, M., Nieto, M., Rivas, J. 2008. Nuevos datos sobre paramoudras y concreciones relacionadas en Jaizkibel e Igeldo (Pseudokarst en arenisca del Flysch Eoceno, Gipuzkoa). Disponible en web: http://www.aranzadi.eus/fileadmin/webs/Publicaciones/pdfs/Paramoudras.T.pdf.

Payros A., Martínez-Braceras, N. 2014. Orbital forcing in turbidite accumulation during the Eocene greenhouse interval. Sedimentology. doi: 10.111/sed..12113

Pujalte, V., Robles, S., Orue-Etxebarria, X., Baceta, J.I., Payros A., Larruzea, I.F. 2000. Uppermost Cretaceous-Middle Eocene strata of the Basque-Cantabrian Region and western Pyrenees: a sequence stratigraphic perspective. Rev. Soc. Geol. España 13: $191-211$

Vera, J.A. (Ed.). 2004. Geología de España. IGME. Madrid 